\title{
Persuasion in Indonesian Food Blogs
}

\author{
Ivena, Clarissa $\mathbf{S}$. \\ English Department, Faculty of Letters, Petra Christian University \\ Surabaya, East Java, Indonesia \\ e-mail: ivena_clarissa@yahoo.com
}

\begin{abstract}
This study is a rhetoric study about the modes of persuasion. The writer chose this topic for her study since she realizes that social media, especially blog, as found in Indonesian food blogs has become inseparable part of people's lives, especially blog, as well as many cafes and restaurants pop up in Jakarta, Indonesia. One thing that has caught the writer's attention and curiosity to write on this particular topic is the way food bloggers persuade or attract their readers through their blogs. The aims of this study were to describe and to analyze the modes of persuasion commonly used in food bloggers post. The writer used Ethos, Pathos, Logos as her framework of analysis. For the sources of data, the writer used the blogs from three famous food bloggers in Jakarta, Indonesia. In this study, the writer herself acted as the instrument of the study. The writer chose and collected the data she needed. Then, she analyzed the data by using several tables. In the findings and discussion, the writer found that the food bloggers mostly use Pathos as their ways to persude the readers. The writer found several categorises in order to analyze the data based on the modes of persuasion such as: ethos consists of ethos through experiences, citing reliable sources, and demonstrating good will. Pathos consists of happy or satisfactory emotions, disappointed or unsatisfactory emotions, and communicate to the readers directly. Logos consists of facts or research, common-sense information, and value.
\end{abstract}

Key words: Ethos, Logos, Pathos, Credibility, Emotion, Logic

\section{Introduction}

In this globalization era, we live in an era where technology has become one of the most essential things in people's life. As the grow of social media such as Facebook, Twitter, Instagram, Blog, and many more, people start to communicate or interact with each other using those kinds of social media. Therefore, people choose social media as one of their advertisement or promotion tools. Blog is one of promotion tools that people use to promote food, we called them food blogs. While, according to a journalist writer Ramya Menon (2015), people who spend their time as restaurants reviewers which are reviewing the quality of food, ambience, service, price range and including their story of why they loved or hated the food are considered as food bloggers.

The reason why food blogging is categorized as persuasion is because the bloggers not only express or tell their experience in general, but also describe everything they have been through in a particular cafe or restaurant in details. However, the blogger must give honest reviews, they do not just tell everything nice about those cafe or restaurant, butalso the dissatisfaction towards the service, the taste of the dish, or anything else. Since food blog gives high impact on the readers, the readers are likely to try or to experience themselves after reading it. Especially here in Indonesia, there are so many cafes and restaurants pop up everywhere. It is easy for us to find a cafe or a restaurant in all over the street. Jakarta, as a metropolitan with the highest number of people brings out so many cafes and restaurants, especially in the middle of teenagers' lives.

Therefore, to analyze the persuasion strategies inside food blog, the writer will use one theory which is the modes of persuasion by Aristotle. The writer chose to use persuasion because food blog is part of persuasion, where by bloggers persuade readers to come to the place that they have reviewed. The writer has two objectives; firstly, the writer wants to analyze the modes of persuasion used in food blogs by three Indonesian food bloggers (Ethos, Pathos, Logos). Secondly, the writer aims to reveal the differences between the three bloggers.

\section{Review of Related Literature}


In analyzing the data, the writer uses a theory and some related studies. The writer uses theory the modes of persuasion in rhetoric by Aristotle using a study on Aristotle rhetoric by Murthy (2014). According to Aristotle, the modes of perusasion consits of three things which are ethos, pathos, and logos. A speaker or writer can use ethos in several ways. Firstly, the speaker or writer begins his or her speech or text by referring their expertise toward the subject that will be discussed. Then, the speaker shares how long he or she has studied the subject or how many articles that he or she published (Brett and McKay, 2010). According to Brett and McKay (2010), another way to build up ethos with the audience or readers is to find common ground with them. The speaker or persuader has to establish shared values and beliefs. By that, it can help the audience to feel the same as the persuaders, then it will make the persuader more trustworthy. Ethos is how the audience see the speaker's credibility and knowledge about the subject (Murthy, 2014). It is about what will the audience think about the speaker when he starts talking. Can they trust them? In order to build credibility of the persuader towards the audience, the persuader requires things such as Personality, Character, Intelligence, Virtue, and Goodwill (Murthy, 2014). The audience will find out the intelligence of the persuader by his knowledge regarding the subject. Meanwhile, Erin (2015) has several tips in order to convince the audience enough, the persuader or writer must provide credibility through experiences, reliable sources, and demonstrating good will.

Pathos is the mood or tone of the speech which attract the audience (demirdöğen, 2010). According to Aho (1985), Pathos relies on the receiver's emotions, before using Pathos, the persuader needs to have the ability or skill such as empathy or emotional intelligence in order to trigger the audience's emotions such as happiness, sadness, satisfaction, pity, or fear (Higgins and Walker, 2012). Houston (2014) stated that many rhetoricians throughout the centuries considered pathos as the strongest of the appeals. Aristotle agrees that pathos proves how the power of emotions can change someones's mind (Rorty, 1996). Houston (2014) adds, people also find more persuasive for the speaker or writer who compliments instead of insults (Rorty, 1996). For Rorty (1996), the audience's emotions also strongly support and determine persuasion (Houston, 2014). Pathos can be used in any occasion for example, a writer wants a reader to evaluate something negatively, so the writer will try to make readers angry. This can also be used for someone's benefit (Rorty, 1996). In order to use Pathos in delivering the argument, Erin (2015) stated several things to do such as: making the audience feel something such as pity, fear, joy, sadness to put the audience in a position to understand the subject. and relating to the audiences.

Logos refers to any intelectual reasons based on logical conclusion. Those conclusion came from solid facts and statistic data. According to demirdögen(2010), Logos is the argument that the persuader advances to appeal to the intelect or reason. It depends on the audience's ability to process information in such logical ways. So, Erin (2015) has several tips in order to convince the audience enough, the persuader or writer must: state the facts. It can be statistics, data, or facts which has evidence, then show that it would be unreasonable not to take the persuader's side, and finally pay attention to the structure and content.

The writer also uses some studies which have been done before to get information related to the study. The thesis entitled Advertising Alcohol: A Rhetorical Analysis of Light-Beer Advertisements" (Gretarsson, 2012) helps the writer to have a better understanding about the modes of persuasion (ethos, pathos, logos). The second thesis entitled Persuasive ways used by multilevel marketer of Tianshi" (Anggraini, 2009), this study helped the writer to find out more about persuasive ways since the study of the writer is also about persuasion.

\section{METHODS}

This study used the qualitative research approach to get and analyze the data. In order to get the data, the writer would analyze the content of food blogs which are in written expression. The writer chose three famous Indonesian food bloggers who write in English. The criteria of the three famous Indonesian food bloggers were based on the same city, namely Jakarta, and the contents or reviews are located in Jakarta. The researcher picked eight blogs from each bloggers, then the researcher analyzed 
each sentences based on the content of each blog one by one. After that the researcher identified and classified the sentences based on the modes of persuasion such as Ethos, Logos, Pathos, the researcher did her best to find out the existing regularities in the data.

This thesis sought to analyze the use of persuasion in food blogs. In order to get into the core meaning of the persuasion being pursued, some degree of interpretation was made (Krippendorff, 2004, p. 16., Schreir, 2013, pp. 1-8, 30). The approach required a close reading of the blogs (cf.Krippendorff, 2004 , pp. 16, 17, 29, 30).In short, the method consisted of: (a) selecting and determining the blogs to be investigated, (b) determining the research questions upon which the writer sought to answer by analyzing the relevant blogs. Then, (c) a close reading of persuasion in the blogs was made, and finally (d) rearticulation of the meaning of the persuasion was made in terms of new analytical narratives.

The unit of analysis in this study was per utterance. Utterance means speech that was bounded by silence. One utterance could be analyzed as more than one persuasive strategy. The writer classified the persuasive utterances based on the customers' age. Furthermore, the writer also separated the data based on Beebe \& Beebe's persuasive strategy theory (2012) and categorized the data into the methods of persuasive strategies. After that, the writer found the persuasive strategy that was mostly used by insurance agents in prospecting different-age (older) customers and same-age customers by calculating the percentage of each method and strategy.

\section{FINDINGS AND DISCUSSION}

Firstly, the writer would answer the first research question; The modes of persuasion used in food blogs by three Indonesian bloggers (ethos, pathos, logos).

The first type of ethos is ethos through experiences. In order to categorize the sentences on the blogs as Ethos, the writer found that the bloggers show their credibility through telling their experience or giving knowledge about other information. In telling their experiences and reviewing the food and services, the bloggers need to deal with their emotion so that the readers can feel what the the bloggers feel at the moment. Since the bloggers use the written form in expressing their emotions, the way they explain or express their emotions will be very limited because they cannot use their gestures or facial expressions in delivering the messages. The writer found several examples of Ethos through experience inside the bloggers' blog, the experiences are expressed in the following sentences,

(A.1) I had a good history with Cassis on my first visit here when it's still known as a French fine dining restaurant.

(A.2) I clearly had better impression to Hatchi comparing to the first time I went to H, and I am glad that $H$ food is now getting better and better.

The credibility of the bloggers in the sentence (A.1) and (A.2) shown through the statements "my first visit", "comparing to the first time I went to H", those examples or sentences are the signs that the bloggers have been to the place before, so it was their second time visiting the place. If the bloggers have never been to the places, how can the readers believe what the bloggers have stated? That is why it is important to determine the readers' beliefs to be successful in building credibility (Smith, 2004). So, by stating them, the bloggers are able to gain their readers' trust and they can be reliable sources. From those sentences, the blogger has successfully provedhis credibility to the readers.

The second type of ethos is citing reliable sources. Telling the experiences of the bloggers are not enough to determine ethos. Ethos also can be found through giving reliable information. For example: (A.6) At its birth place in Kuala Lumpur, Buns \& Meat has taken the city by storm through the power of pork; it was simultaneously listed as one of the best Restaurants, Best Burgers, Best French Fries, and Best Ribs in KL by the Food Advisor, Malaysia's food directory website.

The sentence is classified as Ethos because it stated as reliable information or source which can be seen on "Food Advisor, Malaysia's food directory website". Towards that direction, it is true that the bloggers need to strengthen their credibility by giving support through citing reliable informations.

The last type of ethos is demonstrating good will. ethos requires a personal relationship with the audience (Ronald, 1990), or in other words the speaker or the blogger needs to build a personal communication with the audience or readers. For example: 
(A.3) As for the cake, well I honestly know where they got this cake from but I just don't need to spill it here for you.

(A.13) I'm excited to share with you the latest fresh Japanese fluffly cake which recently opened in PIK, Fuwa Fuwa, will have their grand opening this Friday, on October 28, 2016!

The sentence in (A.3) showsthat the blogger tries to build personal communication by mentioning "you"which directly refers to the readers. However, this sentence has a deeper meaning for both the blogger and the readers. For the blogger himself, he want the readers to realize his credibility in the subject that eventhough the cafe does not reveal the brand of the cake, he knows where the cake comes from but he keeps it to himself so that the readers are curious as stated in "I honestly know where they got this cake from". Whereas, for the readers, they easily get the meaning behind the sentence because the blogger uses"you" and since the blogger does not want to reveal the name of the brand, unconsciously the readers want to find out by themselves.

Different from the sentence in (A.3), there are two meanings in the sentence (A.13). Firstly, the blogger wants to give the readers some information that the Fuwa Fuwa will be open on Friday, October 28, 20016. This is shown from the statement "I'm excited to share with you". Secondly, by the blogger stating that it proves that the blogger is exclussively invitedto come to the cafe before they are open for public.

Moving on to pathos, the first type of pathos is happy/satisfactory emotions. The bloggers express a lot of happiness or satisfactory emotions throughout the blogs when they have to give a review on food and place.For instance:

(B.1) My favorite VIP room is the one located at the back near the kitchen area, once I stepped inside I automatically feel like "this is the one I'm going to throw a private event in the future at", I imagined good lighting in the day.

The sentence from (B.1) clearly shows that the blogger feels happy and satisfied with the room by stating "my favorite VIP room". He also describes his feeling towards the room and unconsciously makes a future plan by saying "this is the one I'm going to throw a private event in the future at".

(B.9) The wonderful smell of freshly baked bread wakes me up better than a cup of coffee. It reminds me of a morning in a beachy island during a family holiday many years ago. The smell of bread gets my appetite running.

The blogger in the sentence (B.9) shows his satisfaction towards the food through the phrase "the wonderful smell". So, the readers can clearly feel that the food is good, indeed. However, the blogger does not stop on that statement, in the second sentence he continues with "It reminds me of a morning in a beachy island during a family holiday many years ago." The sentence implies that the smell of the bread is too good that it reminds him of his good experience in the past. Therefore, it is easier to convince the readers as he comes up with his experience.

The second type of pathos is disappointed/unsatisfactory emotions. As bloggers, they are expected to review everything honestly. So, readers will not only find the positive or good things about the place, but also all the negative or unpleasant experience during their cafe visit. Most of their unsatisfactory feeling comes from the food itself as seen in the sentences:

(B.22) This was that one menu that I was so excited about but ended up feeling utterly disappointed. I didn't have any problem with the freshness of the pork skin, I think it was beautifully crunchy and as you can see pretty generous, but there was NO flavor, not even a single hint of salty.

The sentence in (B.22) can be clearly seen that the blogger is really disappointed by the menu which directly states "disappointed". When the blogger states "the one menu I was so excited about but ended up utterly disappointed", it is implied that at first he actually hopes that the taste of the menu will be delicious but it turns out that the dish has no flavor to his expectation. Moreover, the blogger capitalizes the "no" word in "there was NO flavor.." to affirm and clarifyto the readers that he is really disappointed with the dish.

The last type of pathos is communicate to the readers directly. The last thing that the bloggers do in order to connect their emotions and feelings with the readers is by communicate to the readers directly. Here, the bloggers tend touse "you" directly to the readers aiming as the readers to be able to 
feel and understand the bloggers' emotions at that time. Just like any other pathos that the writer found, here the writer found the example of communicate to the readers directly.

(B.35) My personal favorite has got to the curry soba, just something about the firm and edgy soba that match the flavor of the tasty, rich and creamy sauce, and not to mention, because of the thick curry sauce itself, you can totally experience the maximum flavor of the curry from every strain of the soba, where the sauce is sticking into.

Those sentences above are the examples that the writer found inside the bloggers' blogs when they try to communicate directly with the readers by using "you". In the sentence (B.35), it is clearly seen that the blogger directly speaks to the readers by saying "you can totally experience..". So, in the beginning of the sentence, the blogger stated that his favorite dish is the curry soba (the Japanese name for buckwheat) by stating "My personal favorite has got to the curry soba". Then, after the blogger stated that, he continues giving reasons andargumentation of why he thinks the curry soba (the Japanese name for buckwheat) is the best by explaining what are inside the curry soba (the Japanese name for buckwheat), for instance the sauce. In the middle of the blogger's explanation, then he convinces the readers that the taste is good indeed by telling them that they can totally experience the flavor of the curry. So, the blogger indirectly guarantees the readers that they will share the same mind as the blogger once they try the curry soba (the Japanese name for buckwheat).

Lastly is logos, the first type of logos is facts or research. According to yourdictionary.com "fact" (n.d), fact is something that is true and it has been proven. For instance:

(C.4) The Burgo Three Chili Burger consist of 130 gram house grind Australian beef patty, chipotle aioli, tangy green chili, cilantro relish and served with deep fries as the side dish.

The entire words in (C.4) contain facts because the bloggers is basically informing the readers aboutthe toppings insideThe Burgo Three Chili Burger. This can be seen from the sentence that the blogger mentions the toppings one by one, which means that it is a fact when the readers visit The Burgo and order the Three Chili Burger, they will find the same topping as what the blogger has described.

While for research, according to oxforddictionaries.com "research" (n.d) research is a structured investigation of a study and sources to come up with facts and new conclusions. Since the blogger cannot do a scientific research, the research can be seen by identifying it throughthe bloggers' experiences in the past. For instance:

(C.1) The price list was clearly more pocket friendly even though it's still the Jakarta posh cafes standard pricing where it's medium above. Price range for food starts from IDR 45k-550k and drinks around IDR 30k-100k (alcohol).

The sentence in (C.1) shows that the blogger gives information about the standard pricing in Jakarta posh cafes. The writer categorizes the sentences as a research because the blogger is able to knowthe price range for Jakarta posh cafe, which means he has been to a lot of cafes and that is why he can come up with his conclusion that the price in Cassis Kitchen Jakarta belongs to the standard pricing of Jakarta posh cafe. The blogger also states the price list of the cafe is pocket friendly which means, the price is still affordable even though they offer medium above. This is the blogger's way to persuade the readers to still visit the cafe by stating "the price list of the cafe is pocket friendly" even though the price belongs to medium above.

The second type of logos is common-sense information. According to Snir (2015), common sense is defined as something concrete, self-evident beliefs and judgements, and accepted by others. So, the writer concludes that common sense is something that is make sense and it deals with experience of a person which is accepted by others. For example:

(C.12) They chose sumo as the icon, because the sumo person requires high-quality food intake very much to maintain their weight. That's make sense!

The last sentence in (C.12) is obviously shown that it is common-sense information because, the blogger gives the reason why the restaurant chose sumo as the icon. It turns out because as a sumo person, they require to eat high-quality food to maintain their weight, and makes sense for both the blogger and the readers. Then, in the original text shown after that sentence, the restaurant provides a lot of varieties of local and international food. 
The last type of logos is value. to businessdictionary.com "value" (n.d.), value is beliefs that is shared by a culture or group and it can influence a person's attitude or behavior. Here is the example that the writer get from the data.

(C.2) Being formerly known as a top notch French fine dining restaurants in town, that somehow makes ordering the steak an essential thing to do here.

The blogger implies the sentence in (C.2) as value and it can be seen from the statement "ordering the steak an essential thing to do here" which means, since that French restaurant is the most visited restaurant in town, that makes people shape their mind that it is necessary to order steak. So, by stating that, the blogger wants to tell and persuade the readers that the steak in that cafe is as tasty as steak in other French restaurants.

Secondly, the writer would answer the second research question; the striking differences between the three bloggers. The writer believes that each of the bloggers have different ways of reviewing restaurants or writing their blogs. Therefore, here the writer will analyse each of the bloggers in using Ethos, Pathos, Logos.

During the analysis of the first blogger, Hans who owns (www.eatandtreats.blogspot.co.id), the writer finds out that Hans reviews all the restaurants in a very long writing and very details. His choice of words is also readers friendly and understandable. So, the writer is interested in analysing the way Hans uses Ethos, Pathos, Logos in each of his blog posts. For ethos, Hans does not only share the price lists of each food pictures, but also he shares his experiences. Whether it is about his older visits to the cafe or just giving information. While pathos, Pathos is the most used appeal by Hans compared to the other two appeals. Since Hans is the one who experiences the food and services, he needs to be able to describe his feeling or emotion to the readers. Therefore, the readers will understand his emotion towards his experience with the food, ambience, and services. Aside from that, he does not only share his happy or satisfactory emotions, but sometimes he also experiences unhappy or unsatisfactory emotions. He is implicitly expresses unhappy or unsatisfactory emotions to the readers. For logos, Hans expresses Logos quite a lot, he uses those three types of logos which facts or research, common-sense information, and value in order to give review.

In analysing the second blogger, Ruby who owns (www.wanderbites.com), The writer finds that in every post of Ruby's blog there will not be a complete set of persuasion appeals (Ethos, Pathos, Logos). This means that there will only be two persuasion appeals that Ruby uses in wiritng his blog posts. For instance, Ethos and Pathos, Pathos and Logos, Logos and Ethos, and so on. The writer finds that Ruby does not show his credibility and express his emotions that much through his blog posts. The writer also finds that Ruby's blog posts are lacking of logos.

The last blogger that the writer analysed is Mullie who owns (www.myfunfoodiary.com). from all Mullie's blog posts, the writer finds that the credibility of Mullie is convincingly shown from the way she tells her experiences. Moreover, she tends to show her experiences by telling that she is an invited guest and how people treated her with special. She also uses a lot of pathos in her blog posts, and she is that type of blogger who gives direct reviews. The writer can find each types of Logos from Mullie's blog posts. But, mostly there are many facts (Logos) from her blog posts like giving basic information about new branch of cafe, launching date, and many more.

\section{CONCLUSION AND SUGGESTIONS}

Through the analysis in the findings and discussion chapter, the writer found that all the bloggers do not really pay attention about Ethos, Pathos, Logos in writing their blogs. It can be seen from each blog post that they were being produced by the bloggers, that some of the posts contain the three appeals or only contain two out of three. Moreover, based on the analysis the writer also found that from the three appeals, mostly used appeal is Pathos where the bloggers deal with emotions. This happens because since they are food bloggers, they need to review all things about the restaurant such as the food, service, and ambience. Then, logos comes second where the bloggers deal with logic and information. While, the interesting part is that ethos is the least used appeal by the bloggers. Where the bloggers supposed to use it frequently since it deals with their credibility as bloggers. However, what makes the bloggers can be 
reliable sources for their readers is through pathos. How the bloggers deal with their emotions and experience, and also they communicate with the readers through it.

At the end of classifying and analysing all the data, the writer ends with a conclusion that all the bloggers write their thoughts or opinion in their blog without knowing how to apply Ethos, Pathos, and Logos inside their blog posts. This was seen from the inconsistency of using the complete three appeals for each blog posts. But, according to the analysis, the three blogger have their own ways to writer their blogs. Unconsciously in writing food blog, the bloggers more often use Pathos which happens to be the most effective way to deal with the readers' emotions and to persuade them.

\section{REFERENCES}

Aho, J. (1985). Rhetoric and the invention of double entry bookkeeping. Rhetorica: A journal of the History of Rhetoric, 3, 21-43.

Anggraini, D. (2009). Persuasive ways used by multilevel marketer of tianshi. Retrieved from http://dewey.petra.ac.id/catalog/ft_detail.php?knokat=12946

Brett \& McKay, K. (2010, December 21). Classical rhetoric 101: The three means of persuasion. Retrieved from http://www.artofmanliness.com/2010/12/21/classical-rhetoric-101-the-threemeans-of-persuasion/

Danial, H. Eat and Treats. Retrieved from http://eatandtreats.blogspot.co.id/

Demirdöğen, Ü. D. (2010). The roots of research in (political) persuasion: Ethos, pathos, logos and the yale studies of persuasive communications. p. 192.

Erin, H. (2015, March 9). Ethos, pathos, logos: Be more persuasive in your next essay. Retrieved from https://www.kibin.com/essay-writing-blog/ethos-pathos-logos/

Fact. (n.d.). Retrived from http://www.yourdictionary.com/fact

Gretarsson, G. S. (2012). Advertising Alcohol: A Rhetorical Analysis of Light-Beer Advertisements.

Higgins, C.; Walker, R. (2012). Ethos, logos, pathos: Strategies of persuasion in social/environmental reports. p. 198.

Marlina, M. My Fun Food Diary. Retrieved from http://myfunfoodiary.com/\#sthash.VBeZLzak.dpbs

Menon, R. (2015). What is food blogging and how to become a food blogger. Retrieved from https://medium.com/cucumbertown-magazine/what-is-food-blogging-and-how-to-become-afood-blogger-2b8a6f96a07d

Murthy, D. M. (2014). A study on aristotle's rhetoric. p. 251.

Research. (n.d.). Retrived from https://en.oxforddictionaries.com/definition/research

Rorty, A. O. (1996). Essays on aristotle's rhetoric. Berkeley and Los Angeles, CA: University of California Press.

Ruby, F. Wanderbites. Retrieved from https://www.wanderbites.com/ 